\title{
Advances in Distinguishing
}

\section{Groundwater Influenced by Oil Sands}

Process-Affected Water (OSPW) from

Natural Bitumen-Influenced

\section{Groundwaters.}

Hewitt, LM

http://hdl.handle.net/10026.1/16193

10.1021/acs.est.9b05040

Environ Sci Technol

All content in PEARL is protected by copyright law. Author manuscripts are made available in accordance with publisher policies. Please cite only the published version using the details provided on the item record or document. In the absence of an open licence (e.g. Creative Commons), permissions for further reuse of content should be sought from the publisher or author. 


\section{Advances in Distinguishing Groundwater Influenced by Oil Sands Process-Affected Water (OSPW) from Natural Bitumen-Influenced Groundwaters}

L. Mark Hewitt,* James W. Roy, Steve J. Rowland, Greg Bickerton, Amila DeSilva, John V. Headley, Craig B. Milestone, Alan G. Scarlett, Susan Brown, Christine Spencer, Charles E. West, Kerry M. Peru, Lee Grapentine, Jason M.E. Ahad, Hooshang Pakdel, and Richard A. Frank

Cite This: Environ. Sci. Technol. 2020, 54, 1522-1532

Read Online

ABSTRACT: The objective of this study was to advance analytical methods for detecting oil sands process-affected water (OSPW) seepage from mining containments and discriminating any such seepage from the natural bitumen background in groundwaters influenced by the Alberta McMurray formation. Improved sampling methods and quantitative analyses of two groups of monoaromatic acids were employed to analyze OSPW and bitumen-affected natural background groundwaters for source discrimination. Both groups of monoaromatic acids showed significant enrichment in OSPW, while ratios of $\mathrm{O}_{2} / \mathrm{O}_{4}$ containing

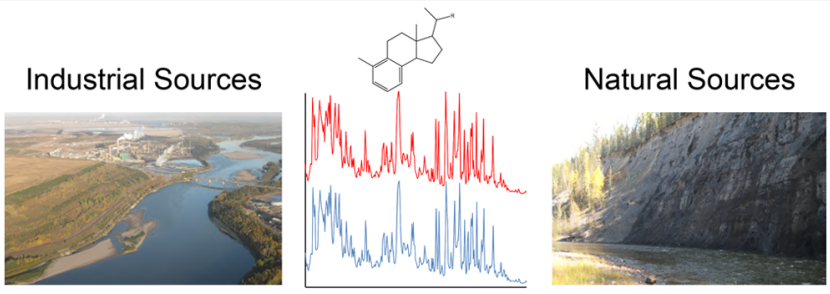

Source Differentiation heteroatomic ion classes of acid extractable organics (AEOs) did not exhibit diagnostic differences. Evaluating the monoaromatic acids to track a known plume of OSPW-affected groundwater confirmed their diagnostic abilities. A secondary objective was to assess anthropogenically derived artificial sweeteners and per- and polyfluoroalkyl substances (PFAS) as potential tracers for OSPW. Despite the discovery of acesulfame and PFAS in most OSPW samples, trace levels in groundwaters influenced by general anthropogenic activities preclude them as individual robust tracers. However, their inclusion with the other metrics employed in this study served to augment the tiered, weight of evidence methodology developed. This methodology was then used to confirm earlier findings of OSPW migrations into groundwater reaching the Athabasca River system adjacent to the reclaimed pond at Tar Island Dyke.

\section{INTRODUCTION}

The Alberta oil sands deposit in Canada is the third-largest proven oil reserve in the world, comprising $142000 \mathrm{~km}^{21,2}$. Mined oil sands undergo a caustic hot water extraction process to separate bitumen from the sand. The byproduct of this extraction, known as oil sands process-affected water (OSPW), is a complex mixture of dissolved inorganic and organic compounds. The organics fraction includes naphthenic acids (NAs) for which the aquatic toxicity has been well documented, ${ }^{3-9}$ although the chemical classes causing toxicity within the greater group of acid extractable organics (AEOs) have yet to be established.

To date, the oil sands industry has not treated and released OSPW and has operated under a zero-discharge practice with accumulated OSPW stored in large containments (tailings ponds), comprising a total area of $>130 \mathrm{~km}^{2} .{ }^{10}$ Despite containment infrastructures (interceptor wells, ditches, and relief wells), designed to capture and return seepage to the ponds, ${ }^{11}$ the question remains as to whether OSPW-affected groundwaters migrate beyond such containments, ${ }^{12-14}$ reach surface waters, ${ }^{15-21}$ and cause adverse effects. Seepage into groundwater from containments adjacent to the Athabasca River or its tributaries are of concern because if seepage is pronounced, there is potential for aquatic life exposures to OSPW-derived toxic substances.

In the case of the Mildred Lake Settling Basin (MLSB) containment, an OSPW-affected groundwater plume has been distinguishable from ambient local groundwater by elevated concentrations of routinely measured parameters, including salts or NAs. ${ }^{13}$ However, the detection of potential seepage at other ponds is hindered by several factors. First, inorganic and organic OSPW compositions closely resemble those in natural bitumen-affected groundwater within the McMurray geological formation. ${ }^{16,20,21}$ Further, as the caustic aqueous extraction of bitumen does not require the addition of industrial additives, potential tracers of OSPW migration are not readily available.

Received: August 21, 2019

Revised: December 13, 2019

Accepted: January 6, 2020

Published: January 6, 2020 


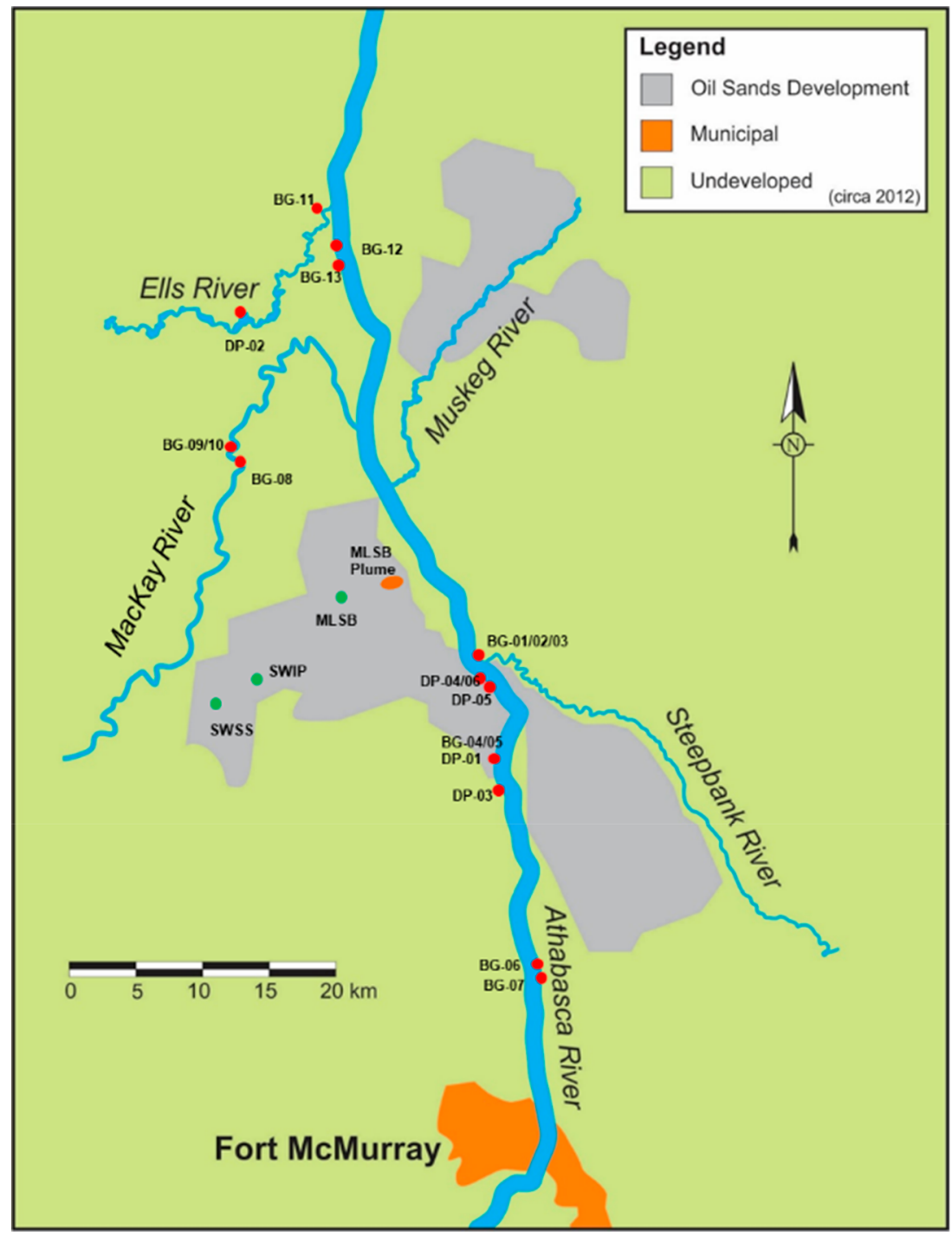

Figure 1. Overview map of the study area of the oil sands region north of Fort McMurray, AB, Canada, showing sampling sites for OSPW (green symbols), the MLSB plume (orange oval; individual well locations not shown) and riparian groundwater (red dots) comprising Background (BG-1 to 13; DP-1 to 3) and Unknowns (DP-4 to 6) by Tar Island Dyke (TID). Sample details are provided in Table 1.

Finally, despite recent discoveries of adamantane, ${ }^{22,23}$ bicyclic $\mathrm{NAs},{ }^{24,25}$ and alicyclic, aromatic, and sulfur-containing acids $^{23,26}$ in OSPW, there are few commercially available authentic standards of OSPW constituents, hampering efforts to develop and standardize analytical methodologies for NAs and seepage detection.

In previous attempts to identify OSPW-affected groundwater, a wide range of chemical metrics has been applied. These have included: measurement of total NAs, arsenic, boron, fluoride, molybdenum, selenium, vanadium, nickel, rhenium, ammonium, sodium, and chloride and their ratios, characterization of water types (Piper plots), use of synchronous fluorescence spectroscopy (SFS) to determine aromatic species, monitoring of a variety of isotopic tracers from ${ }^{2} \mathrm{H}$ and ${ }^{18} \mathrm{O}$ of water to dissolved ions and to measurement of intramolecular $\delta^{13} \mathrm{C}$ signatures, determination of the ratios of $\mathrm{O}_{2} / \mathrm{O}_{4}$ heteroatom classes, and the presence of $\mathrm{SO}_{n}$ containing species in OSPW. ${ }^{13,17,18,20,27-38}$ Since 2005, with advances in available analytical instrumentation and an improved understanding of the organic compositions of OSPW, ${ }^{22,24-26,39,40}$ studies on NAs as tracers of OSPW migration have expanded to include the broader class of AEOs and have progressed from standard gas chromatography-mass spectrometry (GC-MS) methodologies ${ }^{18}$ to deployment of state of the art instrumentation, including high performance liquid chromatography-time-of-flight mass spectrometry (HPLC-ToF-MS ${ }^{19}$ ), HPLC-high resolution mass spectrometry (HPLC-HRMS ${ }^{21}$ ), comprehensive multidimensional GC-MS $\left(\mathrm{GC} \times \mathrm{GC}^{-\mathrm{MS}^{16,41}}\right)$, and Fourier transform-ion-cyclotronresonance mass spectrometry (FT-ICR-MS ${ }^{29,34,35,42}$ ). It is important to note that although the ability to characterize bitumen influence has evolved through these studies, the differentiation of OSPW-affected groundwaters from natural bitumen sources has not been achieved. The analytical challenge in source discrimination of these inherently similar, so-called "supercomplex" 43 mixtures, is considerable.

The only study to assert some success in this endeavor was that of Frank et al. ${ }^{16}$ that applied a tiered, weight of evidence approach that included routine analytical methods (Level-1) and two advanced methods for profiling AEOs (Level-2) to directly compare each source. One Level-2 method used GC $\times$ GC-TOF-MS to identify two groups of monoaromatic 
naphthenic acids (denoted "Family A and B") shown to be elevated in OSPW and OSPW-influenced groundwater. The other Level-2 method used high resolution mass spectrometry (HRMS) profiling of AEOs to associate OSPW influence with a greater proportion of $\mathrm{O}_{2}$ heteroatom ion classes relative to $\mathrm{O}_{4}$ species, although subsequent studies have shown conflicting evidence regarding such ratios to differentiate source. $^{21,34,35}$ Both Level-2 methods demonstrated source differences for two samples of shallow groundwater collected adjacent to Tar Island Dyke (TID) at the edge of the Athabasca River, which the authors concluded were likely influenced by OSPW. ${ }^{16}$ While this study showed promise in differentiating groundwaters affected by OSPW from those influenced by natural bitumen sources, limitations included the extent of sampling within each source type and the qualitative capability of the Level-2 analyses.

The primary objective of the present study was to explore further the utility of the Family $\mathrm{A}$ and $\mathrm{B}$ groups of monoaromatic acids, and ratios of $\mathrm{O}_{2} / \mathrm{O}_{4}$ classes, to distinguish OSPW-affected groundwater from ambient groundwater influenced by the natural bitumen deposits of the McMurray Formation. This was accomplished through sampling and analysis improvements that included the (i) use of larger sample volumes (>1000 fold) to facilitate the greatest possible level of detection; (ii) quantitation of the Family A and B acids; (iii) use of a larger set of OSPW (2 different mining operations per parameter); (iv) use of a larger set of natural "background" groundwaters from the area where the McMurray formation outcrops, including several that were fairly saline; and (iv) validation of the combined methodology against a known plume of OSPW-affected groundwater. ${ }^{13}$

A secondary objective was to assess whether anthropogenic artificial sweeteners and per-and polyfluoroalkyl substances (PFAS) have diagnostic capabilities as tracers of OSPW seepage. Both groups are hypothesized to have some diagnostic capabilities due to their association with anthropogenic activities, persistence and mobility in groundwater, and utility in contaminant source apportionment. ${ }^{44-48}$ The final objective was to reassess the presence of OSPW-affected groundwater at select locations at the edge of the Athabasca River adjacent to TID, as indicated by Frank et al., ${ }^{16}$ using the improved methodology.

\section{METHODS}

Sample Collections. Sample locations are presented in Figure 1 and sampling details are summarized in Table 1 . OSPW samples were collected with stainless dippers into precleaned stainless steel containers fitted with Viton seals or glass bottles, with assistance and access provided by the respective oil sands operators' personnel. Shallow riparian groundwater samples were collected using a stainless steel drive-point system ${ }^{49}$ at depths of $30-120 \mathrm{~cm}$ below the streambed of the Athabasca River and associated tributaries (Figures S1-S3). The locations (e.g., edge of river, outside of meanders) and timing (e.g., low river flow periods) of sampling were all chosen to best ensure collection from groundwater discharge zones. Furthermore, the drive point was pushed deeper prior to sampling if the water quality parameters indicated a similarity to surface water, which might indicate hyporheic exchange. Sampling included a repeat sampling of 3 background sites ( $>1 \mathrm{~km}$ from any OSPW influence) and 3 sites adjacent to TID ("unknowns") initially sampled by Frank et al. ${ }^{16}$ and was followed by collections from 13 additional
Table 1. Sets of samples collected for this study (locations shown in Figure 1$)^{a}$

\begin{tabular}{|c|c|c|}
\hline $\begin{array}{l}\text { Sample } \\
\text { Groupings }\end{array}$ & $\begin{array}{l}\text { Number of } \\
\text { samples }\end{array}$ & Notes \\
\hline OSPW & $\begin{array}{l}5 \text { ponds } \\
\text { sampled from } \\
2 \text { operators }\end{array}$ & $\begin{array}{l}\text { 1. Syncrude Mildred Lake Settling Basin } \\
\text { (MLSB); September } 2010 \text { \& } \\
\text { December } 2013 \\
\text { 2. Canadian Natural Resources Limited } \\
\text { (CNRL); September } 2011 \\
\text { 3. Syncrude West In-Pit (WIP); } \\
\text { September } 2011 \\
\text { 4. Syncrude Southwest In-Pit (SWIP), } \\
\text { August } 2015 \\
\text { 5. Syncrude Southwest Sand Storage } \\
\text { (SWSS), September } 2015\end{array}$ \\
\hline $\begin{array}{l}\text { Background } \\
\text { Groundwater }\end{array}$ & 16 & $\begin{array}{l}13 \text { new locations (BG, within McMurray } \\
\text { formation, near surface) (August } \\
2013 \text { ) } \\
\text { Resampled Drive-points (DP) } 1-3 \text { from } \\
\text { Frank et al. }{ }^{16} \text { (September 2012) }\end{array}$ \\
\hline $\begin{array}{l}\text { MLSB plume } \\
\quad \text { (Figure 3) }\end{array}$ & 12 & $\begin{array}{l}\text { In Plume: 01A, 01B, 02B, 02C, 03B, } \\
\text { 03C, 04B } \\
\text { Nonplume: 03A, 04A, 05B, 05C, 06A } \\
\text { All sampled December } 2013\end{array}$ \\
\hline $\begin{array}{c}\text { Unknowns by } \\
\text { TID }\end{array}$ & 3 & $\begin{array}{l}\text { Resampled DP 4-6 from Frank et al. }{ }^{16} \\
\text { (September 2012) }\end{array}$ \\
\hline $\begin{array}{l}{ }^{a} \text { Including oil } \\
\text { ponds, shallow } \\
\text { Tar Island Dy } \\
\text { Settling Basin }\end{array}$ & $\begin{array}{l}\text { ds process } \\
\text { rian ground } \\
\text { and ground } \\
\text { icated as ins }\end{array}$ & $\begin{array}{l}\text { ter (OSPW) from several tailings } \\
\text { ter (Background and Unknowns by } \\
\text { ater from wells near Mildred Lake } \\
\text { e/outside the OSPW plume }{ }^{13} \text { ). }\end{array}$ \\
\hline
\end{tabular}

background sites. Finally, MLSB OSPW and groundwater from 6 sets of nested wells (each with wells at $1-3$ depths) along the MLSB plume ${ }^{13}$ were collected (Figures 1 and 3). All groundwater sampling commenced following purging of the well or mini-profiler system and equilibration of fieldparameters (temperature, electrical conductivity, $\mathrm{pH}$, dissolved oxygen) measured with hand-held meters. No surface water sampling was conducted.

Samples for standard geochemistry (i.e., ammonium, major ions, metals, alkalinity) and artificial sweeteners were collected in separate bottles and preserved as described (Table S1). In addition, a large volume sample for Level-2 profiling, total NAs, SFS, and PFAS analysis was collected in an $18 \mathrm{~L}$ stainless steel collection vessel fitted with a Viton seal. All samples were refrigerated on the day of collection, shipped at $4{ }^{\circ} \mathrm{C}$ to Burlington, $\mathrm{ON}$ within 1 week of collection, and stored at 4 ${ }^{\circ} \mathrm{C}$. Subsampling and extraction were conducted within 1 week of arrival.

Screening (Level-1) Analyses. Level-1 analyses included geochemical parameters comprising determination of anions (including chloride, sulfate, and nitrate) analyzed by ion chromatography, major cations (including sodium and calcium) analyzed by direct aspiration using an inductively coupled argon plasma mass spectrometry, and ammonium analyzed by spectrophotometry (absorbance of phenolhypochlorite at $640 \mathrm{~nm}^{16}$ ). Alkalinity was determined by titration method $2320 .^{50}$ Samples were analyzed for a suite of trace metals at Environment and Climate Change Canada's National Laboratory for Environmental Testing (NLET) (Burlington, ON) using inductively coupled plasma-sector field mass spectrometry (SOP 2003). Level-1 analyses also included determination of total AEO concentrations (referred to subsequently as NAs). Low resolution ESI-MS analyses for total NAs were conducted with a Quattro Ultima (Waters 
Corp., Milford, MA) triple quadrupole mass spectrometer equipped with an ESI interface operating in negative-ion mode, as described by Frank et al. ${ }^{16}$ Additionally, expected maxima in an SFS profile associated with previously identified mono- and diaromatic acids ${ }^{39}$ were analyzed as described previously. ${ }^{51}$ In this investigation, samples that exhibited the characteristic bitumen profile with three maxima with a signal intensity of 100 at $272 \mathrm{~nm}$ were identified as positive for this profile.

Advanced Separation and High-Resolution (Level-2) Analyses. Samples were extracted for detailed profiling of acidic and neutral bitumen organics by ESI-MS and ESIHRMS. Quantitative determinations of monoaromatic acid Family A (expanded to 8 isomers, using $m / z 145$ ) and B acids ( 2 isomers, using $m / z 237,310$ ), as their methyl esters, were conducted by comprehensive two-dimensional gas chromatography with time-of-flight mass spectrometry $(\mathrm{GC} \times \mathrm{GC}-\mathrm{TOF}-$ MS). For all OSPW samples, $2.0 \mathrm{~L}$ volumes were utilized due to the elevated concentrations expected, whereas 15-18 L were used for all groundwaters. Prior to extraction, samples were acidified to $\mathrm{pH} 2$ with $12.0 \mathrm{M} \mathrm{HCl}$, and extractions were conducted using two $900 \mathrm{~mL}$ dichloromethane aliquots, each with $1 \mathrm{~h}$ thorough mixing within sample collection vessels. Each extract was subsequently evaporated to dryness under a stream of $\mathrm{N}_{2}$ and reconstituted to an initial volume of either $1.0,5.0$, or $10.0 \mathrm{~mL}$ in dichloromethane, depending on source. Aliquots $(0.5-1.0 \mathrm{~mL})$ were withdrawn and methylated with freshly prepared diazomethane for GC $\times$ GC-TOF-MS analysis of monoaromatic acids. The remaining extracts were then adjusted to either 5.0 or $1.0 \mathrm{~mL}$; a $500 \mu \mathrm{L}$ aliquot was removed, solvent exchanged into methanol, and split evenly for (i) ESI-MS analyses of total NAs with profiling by ESI-HRMS and (ii) untargeted profiling by LC-QToF. ${ }^{52}$

Level-2 AEO profiling of sample extracts using ESI-HRMS was performed on a LTQ Orbitrap Elite mass spectrometer (Thermo Fisher Scientific, San Jose, CA) using electrospray ionization in negative ion mode. ${ }^{16}$ Class distributions were determined using acquired accurate mass data and Composer version 1.0.2 (Sierra Analytics, Inc. Modesto, CA) with an $\mathrm{O}_{2}$ mass error of $0.065 \mathrm{ppm}$.

GC $\times$ GC-TOF-MS Analysis of Monoaromatic Acids. Quantitative analysis of the Family A and B monoaromatic acids $^{16}$ were conducted on methylated extracts using an Agilent 7890A GC (Agilent Technologies, Wilmington, DE) fitted with a Zoex ZX2 GC $\times$ GC cryogenic modulator (Zoex Corporation, Houston, TX) interfaced with an Almsco BenchTOFdx TOF-MS (Almsco International, Llantrisant, Wales, UK). The primary column was a $60 \mathrm{~m} \times 0.25 \mathrm{~mm} \times$ $0.25 \mu \mathrm{m}$ Rxi-1 ms (Restek, Bellefonte, U.S.A.), followed by a 1 $\mathrm{m} \times 0.1 \mathrm{~mm}$ deactivated fused silica modulation loop. The secondary column was a $2.5 \mathrm{~m} \times 0.1 \mathrm{~mm} \times 0.1 \mu \mathrm{m}$ BPX50 (SGE, Melbourne, Australia). Samples $(1 \mu \mathrm{L})$ were injected at $300{ }^{\circ} \mathrm{C}$ splitless using a helium carrier at $1.0 \mathrm{~mL} / \mathrm{min}$. Oven programming was from $120{ }^{\circ} \mathrm{C}(5 \mathrm{~min}$ hold $)$ to $250{ }^{\circ} \mathrm{C}$ at 15 ${ }^{\circ} \mathrm{C} / \mathrm{min}$, then to $340{ }^{\circ} \mathrm{C}$ at $2.5^{\circ} \mathrm{C} / \mathrm{min}$, and held for $10 \mathrm{~min}$. The hot jet was programmed to track the primary oven at 100 ${ }^{\circ} \mathrm{C}$ above. The modulation period was $3 \mathrm{~s}$. The MS transfer line temperature was $300{ }^{\circ} \mathrm{C}$ and ion source $275{ }^{\circ} \mathrm{C}$. Data processing was conducted using GC Image v2.3 (Zoex, Houston, TX, U.S.A.) with the CLIC (Computer Language for Identifying Chemicals) expression tool. ${ }^{26,53}$

For this study, quantitation of the Family A and B acids was calibrated on one isomer isolated from an OSPW sample (WIP, sampled in 2009) using preparative GC. Following a protocol used by Ahad et al., ${ }^{27}$ the OSPW extract was repeatedly injected into an Agilent 7890A GC equipped with two $30 \mathrm{~m} \times 0.5 \mathrm{~mm}$ i.d. DB-5MS columns $(0.5 \mu \mathrm{m}$ film thickness) and a flame ionization detector (FID) coupled to a Gerstel (Mülheim an der Ruhr, Germany) preparative fraction collection (PFC) system. Approximately 5\% of the eluent was directed to the FID, with the remainder sent to the PFC. The isolated subfractions were recombined and reinjected into the PFC several times to improve purity. Subfractions were purified by silica gel and analyzed by GC-MS to verify purities.

Anthropogenic Chemicals Analyses. Artificial sweeteners (acesulfame, saccharin) were analyzed with a Dionex 2500 ICS ion liquid chromatography system combined with an Applied Biosystems AB Sciex Q Trap 5500 triple quad mass spectrometer using an electrospray ionization source in negative mode. ${ }^{44}$

Per- and polyfluoroalky substances were concentrated from aqueous samples using weak anion exchange solid phase extraction (SPE) following previously published protocols, ${ }^{54}$ and concentrations were adjusted for surrogate recoveries (Tables S2-S4). While the full suite of perfluoroalkylcarboxylates (four to 14 carbons) and perlfuoroalkylsulfonates (C4, C6, C8, C10) were determined, we focused on perfluorobutane sulfonate (PFBS), perfluorohexane sulfonate (PFHxS), and perfluooroctane sulfonate (PFOS) to highlight sample trends.

Statistical Analysis. Mood's median test was used to test equality of the background and OSPW group medians, as a nonparametric alternative to a one-way ANOVA or $t$ test that is more robust against outliers than a Kruskal-Wallis test. ${ }^{55}$ Differences between background and OSPW group means were tested for significance using $t$ tests assuming unequal group variances. To improve normality of the data and equality of group variances, data were transformed by $\log (x+x \min )-$ $\log (x \min )$, which is appropriate for data with zeros whose smallest positive value is not close to $1 .^{55}$

To assess joint variation among 32 samples from the 4 sample groups (Table 1), Principal Components Analysis (PCA) was conducted on a correlation matrix computed for 31 chemical variables (Level-2 parameters and a select group of Level-1 parameters). Data for all variables except $\mathrm{O}_{2} / \mathrm{O}_{4}$ ratio were log-transformed to improve normality of distributions. Significance of eigenvalues was determined by the broken-stick test. $^{55}$

\section{RESULTS AND DISCUSSION}

Evaluation of Previous Level-2 Metrics with OSPW vs Background Groundwater. The first step in advancing our previous methodology was to evaluate the source discrimination ability of our previously proposed Level-2 metrics ${ }^{16}$ against an expanded set of samples from OSPW and natural groundwater sources. A comparison of background sites and OSPW ponds, analyzed for the Family $\mathrm{A}$ and $\mathrm{B}$ acids and ratios of heteroatomic ion classes $\left(\mathrm{O}_{2} / \mathrm{O}_{4}\right)$, is presented in Figure 2 .

Consistent with the qualitative data from Frank et al., ${ }^{16}$ the quantitative analyses of Family A and B acids showed both are present naturally. Here, both groups showed clear enrichment in OSPW (Family A, 148-fold; Family B, 38-fold based on means), with no overlap in the ranges. Further, the results of the Mood Median tests on untransformed data and $t$ tests on transformed data (Table S5) both indicated significant differences between the OSPW and background samples for the sum of Family A isomers, sum of Family B isomers, and all 


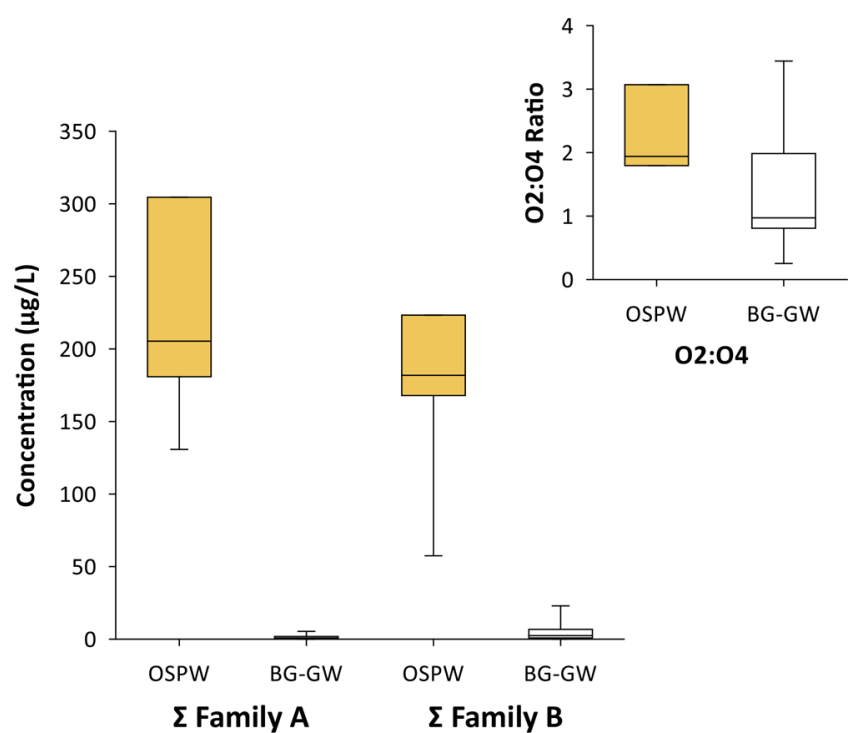

Figure 2. Box plots showing mean and middle quartile (box) and range (whiskers) for total Family A and B monoaromatic acid concentrations and HRMS speciation ratios of $\mathrm{O} 2-$ and $\mathrm{O} 4-$ containing species compared between OSPW ( $n=4$ Family A-B, $n$ $\left.=3 \mathrm{O}_{2} / \mathrm{O}_{4}\right)$ and background groundwater $(\mathrm{BG}-\mathrm{GW} ; n=16)$ samples.

individual $\mathrm{A}$ and $\mathrm{B}$ isomers ( 8 and 2 isomers, respectively). There was clearly less difference for Family B, as the lowest value for OSPW was only 2.5 -fold larger than the maximum of the background groundwater samples; likewise the $t$ test $\mathrm{T}$ value was of lower magnitude for Family B (8.3, compared to 15.4 for Family A). When the individual components were considered, those showing the greatest difference between OSPW and background groundwater (based on the T-value; Table S5) were, in order, isomers A5, A3, A1, A4, with some separation then to A2, A7, A6, A8, and finally B1 and B2. Note also that isomers A5 and A3 were only found above detection limits in two background samples (BG-3, BG-13), whereas all other components were found in four or more background samples (Table S6). The higher concentrations of the Family A and $\mathrm{B}$ acids in OSPW are likely from the caustic bitumen extraction and recycling of water (including evaporative enrichment $^{31}$ ) that leads to a general enrichment of AEOs as a class.

In contrast, ratios of heteroatomic ion classes containing $\mathrm{O}_{2} /$ $\mathrm{O}_{4}$ species from OSPW and background groundwater overlapped, though the OSPW data set was shown to be significantly higher than that of the background groundwaters with the Mood Median Test and $t$ test on transformed data. Both sets had one or more values considered high $(>1)$. While this may be related to the differing bitumen contents within the set of background samples (Figure S4), based on the extensive sampling conducted in this study, the ratios of $\mathrm{O}_{2} / \mathrm{O}_{4}$ species do not clearly differentiate OSPW from background bitumenaffected groundwater. This is consistent with Sun et al. ${ }^{21}$ who reported high $\mathrm{O}_{2} / \mathrm{O}_{4}$ ratios for OSPW (1.2 to 1.8$)$ but also for far-field natural groundwater (A5w-GW; ratio of 1.3). Similarly, Yi et al. ${ }^{34}$ also reported a wide range of $\mathrm{O}_{2} / \mathrm{O}_{4}$ ratios that overlapped among sample types.

Given these results, we next sought to evaluate the ability of the Family A and B compounds to identify known OSPWaffected groundwater. For validation, we sampled the monitoring well network of the known OSPW-affected groundwater plume emanating from MLSB (tailings pond;
Figure 3). Locations deemed "in plume" (i.e., 01A, 01B, 02B, 02C, 03B, 03C, 04B) and outside the plume (i.e., 03A, 04A,

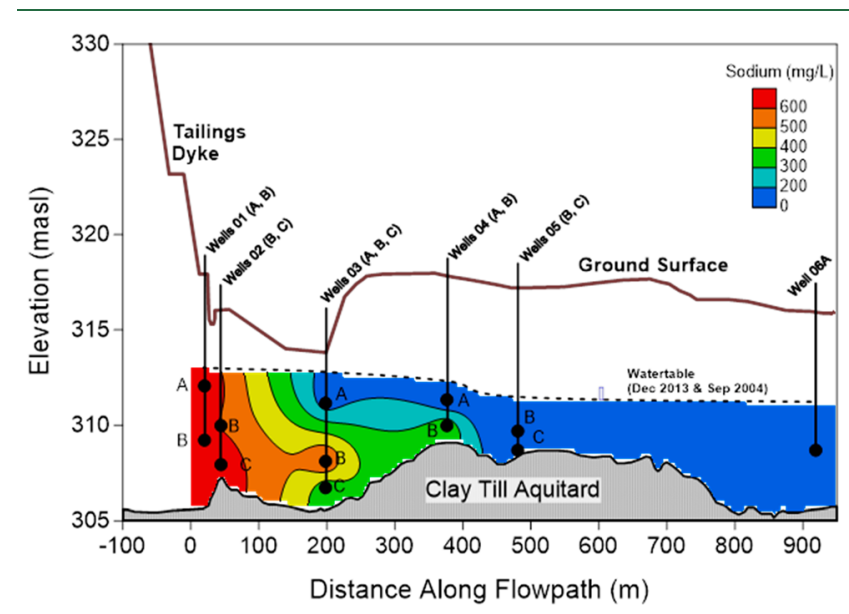

Figure 3. Schematic cross section of the Mildred Lake Settling Basin (MLSB) plume showing: base of constructed tailings dyke; ground surface elevation; well and associated sample intake locations; water table location measured in December 2013 and September 2004; ${ }^{15}$ and contour of December 2013 data as defined by sodium concentration $\left(\right.$ c.f. $\left.^{15}\right)$. Note that plume contours and inferred extent differed somewhat for the different chemical tracers considered. Elevations in meters above sea level (masl). Modified after. ${ }^{15}$

05B, 05C, 06A; "non-plume") have not changed from what was first reported, ${ }^{13}$ based on total NAs, sodium (Figure 4) and other Level-1 metrics (i.e., SFS, boron, fluoride; Figure S5). While this plume can be distinguished from the surrounding and relatively pristine groundwater by routine analyses (i.e., major ions, ammonium, and total NAs), it is nevertheless important that potential OSPW-tracers, such as the Family A and B compounds, be assessed in their ability to identify OSPW-affected groundwater throughout the length of the plume. A robust OSPW tracer should be able to match OSPW of present and historical conditions. Here, changes across the extent of the plume could reflect changes in pond composition over the past few decades (i.e., locations closer to the source MLSB representing more recent OSPW conditions; further locations representing more historical conditions). Second, an ideal OSPW tracer would not be slowed substantially by sorption or removed by degradation processes $^{56}$ during transport through the aquifer.

The monoaromatic Family A and B acids showed good utility for identification of the plume (Figure 4A) paralleling the concentrations of total NAs and sodium (and chloride, Figure 4B), where the elevated concentrations at well 4A, may reflect faster transport of this conservative ion. The leading edge of the plume is indicated at well site 4 where the deeper $4 \mathrm{~B}$ sample is the last sample to show OSPW-affected groundwater by these metrics. The absence of detectable Family A and B acids in samples from wells 5 and 6 combined with the lower concentrations present in samples from shallow wells $3 \mathrm{~A}$ and $4 \mathrm{~A}$ also reflect the nature of the background at this site, which is affected minimally by natural bitumen (Figure $4 \mathrm{~A}^{13}$ ). Interestingly, when expressed relative to the totals measured in the OSPW sample from MLSB, the Family $A$ acids were generally reduced throughout the plume, whereas the Family B acids were consistent or elevated. Further differences were apparent between the individual components (Figures S3, S4). For instance, isomers A1-A4 and especially 

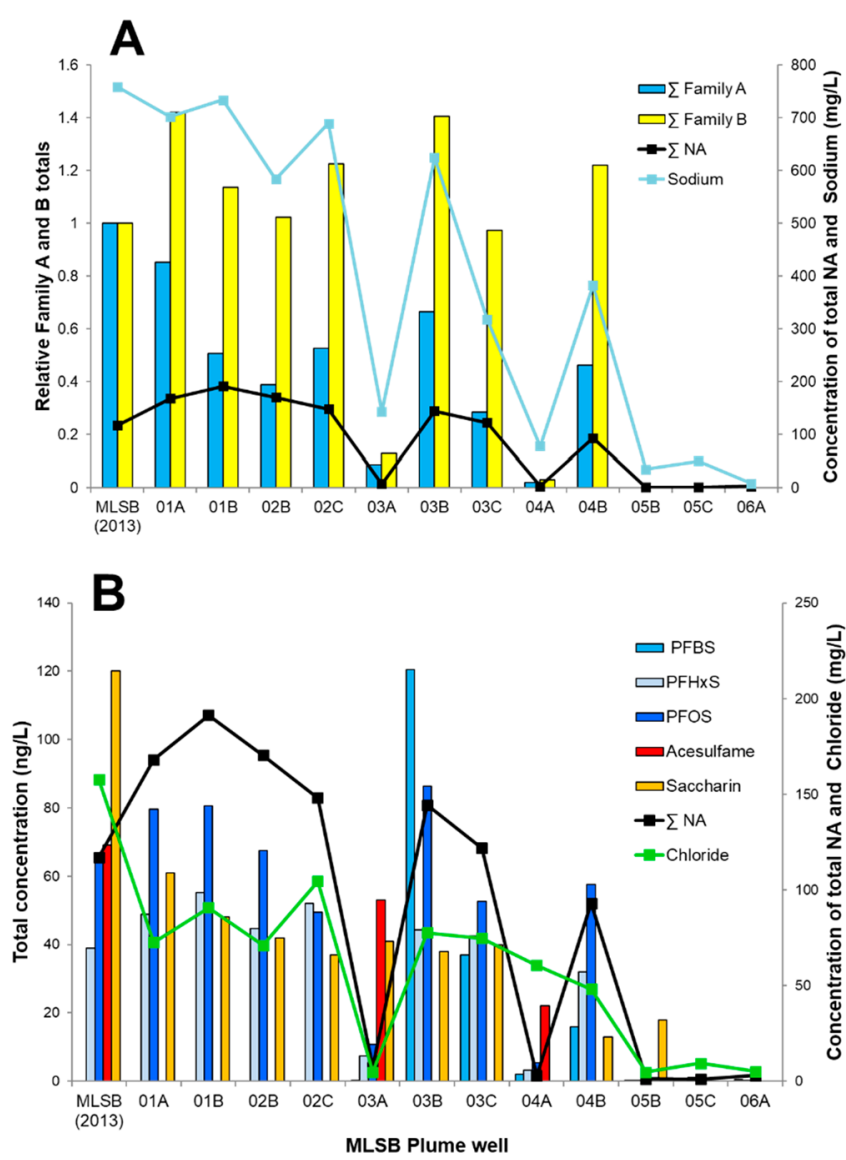

Figure 4. Total Family A and B monoaromatic acids (A), artificial sweeteners (acesulfame and saccharin) and PFAS surfactants (PFBS, PFHxS, PFOS) (B) present in well samples of the MLSB plume monitoring network and the OSPW-source MLSB tailings pond and are arranged from left in direction of flow path. Panel A depicts total monoaromatic acids expressed relative to the source OSPW. Results are plotted against Total NAs, ( $\mathrm{NA}$, black line), chloride- and sodium+ ions (green and blue lines, respectively), which have been previously shown to delineate the plume at this site. ${ }^{13}$

A6 were found throughout the plume at levels only slightly lower than the source OSPW (Figure S5), attributable to dilution, biodegradation/sorption, or enrichment in the source OSPW over time. In contrast, isomers A5, A7, and A8 were at much lower levels or absent from wells at the front of the plume (e.g., 3C, 4B; Figure S6), possibly due to sorption or biodegradation within the aquifer. ${ }^{56}$ Alternatively, this may reflect a historical change in OSPW composition, making them less diagnostic. Of the Family B components, B2 showed a general enrichment relative to the source OSPW, while B1 was consistent (Figure S7). It is possible that B2 is a degradation product or its concentration in OPSW has declined recently. In conclusion, this evaluation supports the utility of using the Family A and B combination as tracers of OSPW as they appear capable of application to historical conditions and generally behave conservatively when grouped, with some individual isomer differences noted during transport in this groundwater flow system. We note that this conclusion is based on the MLSB groundwater plume and results may differ at other ponds under other geological conditions.

Evaluation of Anthropogenic Chemicals. Artificial sweeteners and PFAS are two groups of anthropogenic contaminants known to be highly mobile and persistent in groundwater with source apportionment capabilities. ${ }^{44-48}$ Despite the fact that they may not be unique to OSPW, their presence in OSPW may augment a weight of evidence approach. Artificial sweeteners were analyzed in 10 OSPW samples from three tailings pond sites, with concentrations of acesulfame and saccharin ranging from nondetect $(<8 \mathrm{ng} / \mathrm{L})$ to $530 \mathrm{ng} / \mathrm{L}$ and $\sim 30$ to $420 \mathrm{ng} / \mathrm{L}$, respectively, significantly enriched over background groundwater (Figure S8).

The elevated amounts of sweeteners in many of these OSPW samples may result from tailings ponds historically receiving treated or untreated on-lease wastewater. They may also be derived via recycling of Athabasca River water containing these substances from upstream sources, during bitumen extraction. These compounds would typically be below detection limits for pristine waters. However, groundwater may be affected by other sources associated with oil sands developments, including wastewater treatment plants (WWTPs) and septic systems. For example, in a study of urban groundwater, ${ }^{44}$ four sites (three with known wastewater influences) had maximum acesulfame concentrations $>2500$ $\mathrm{ng} / \mathrm{L}$ and two sites (one wastewater, one landfill influenced) had maximum saccharin concentrations $>2000 \mathrm{ng} / \mathrm{L}$. Similarly, in a study of 12 septic system sites, Robertson et al. ${ }^{57}$ found that acesulfame concentrations in groundwater plumes were typically $>2000 \mathrm{ng} / \mathrm{L}$. Finally, one background groundwater sample of Roy et al., ${ }^{20}$ collected along the Athabasca River in the oil sands area and near a WWTP had (unreported) acesulfame and saccharin concentrations of 290 and $50 \mathrm{ng} / \mathrm{L}$, respectively. Thus, these other sources, which may occur near the tailings ponds in association with anthropogenic activity, combined with the low concentrations found in some tailings ponds may confound the identification of OSPW-affected groundwater using artificial sweeteners alone.

In this study, OSPW concentrations of PFBS, PFOS, and PFHxS ranged from nondetection $(0.03 \mathrm{ng} / \mathrm{L})$ to $60 \mathrm{ng} / \mathrm{L}, 0.5$ to $75 \mathrm{ng} \mathrm{ng} / \mathrm{L}$, and 0.2 to $97 \mathrm{ng} / \mathrm{L}$, respectively (Figure S9). The origin(s) of the PFAS in OSPW are not presently known. The predominant historical usage of PFOS is in aqueous film forming foams (AFFF) for fighting fuel-based fires. ${ }^{58}$ Due to the industrial manufacturing process, PFOS-based AFFF also contains PFBS and PFHxS as minor impurities. ${ }^{59}$ Given that the profile of PFAS congeners in OSPW did not resemble that of the Athabasca River and its tributaries, particularly considering the relatively low levels of perfluorooctanoate (PFOA) and perfluorononanoate (PFNA), recycling of Athabasca River water containing these substances from upstream sources during bitumen extraction can be eliminated as a source (Figure S10). For example, in OSPW samples, the concentrations of PFOA ranged from $\angle \mathrm{LOD}$ to $9.5 \mathrm{ng} / \mathrm{L}$ and those for PFNA ranged from <LOD to $0.20 \mathrm{ng} / \mathrm{L}$, and similarly, the concentrations in the Athabasca River itself were $0.93 \pm 0.33 \mathrm{ng} / \mathrm{L}$ PFOA, $0.097 \pm 0.006 \mathrm{ng} / \mathrm{L}$ PFNA, <LOD PFHxS, $0.40 \pm 0.05 \mathrm{ng} / \mathrm{L}$ PFOS, and $7.9 \mathrm{ng} \pm 2.1 \mathrm{ng} / \mathrm{L}$ PFBS. Conversely, the elevated presence of PFOS, PFBS, and PFHxS in OSPW relative to background groundwaters (Figure S9), and their relative similarities to AFFF, suggest the mining operation as a source. These findings are consistent with Dauchy et al. ${ }^{60}$ that showed high levels of PFOS (9.5-19 $\mu \mathrm{g}$ / $\mathrm{L})$, PFBS $(0.2-0.6 \mu \mathrm{g} / \mathrm{L})$, and PFHxS $(1.3-2.7 \mu \mathrm{g} / \mathrm{L})$ in a wastewater lagoon sampled from an oil refinery that conducted on-site AFFF training. Similarly, Milley et al. ${ }^{61}$ indicated that commercial and military airports are sources of PFAS when $\mathrm{AFFF}$ is released during training, emergency responses, 


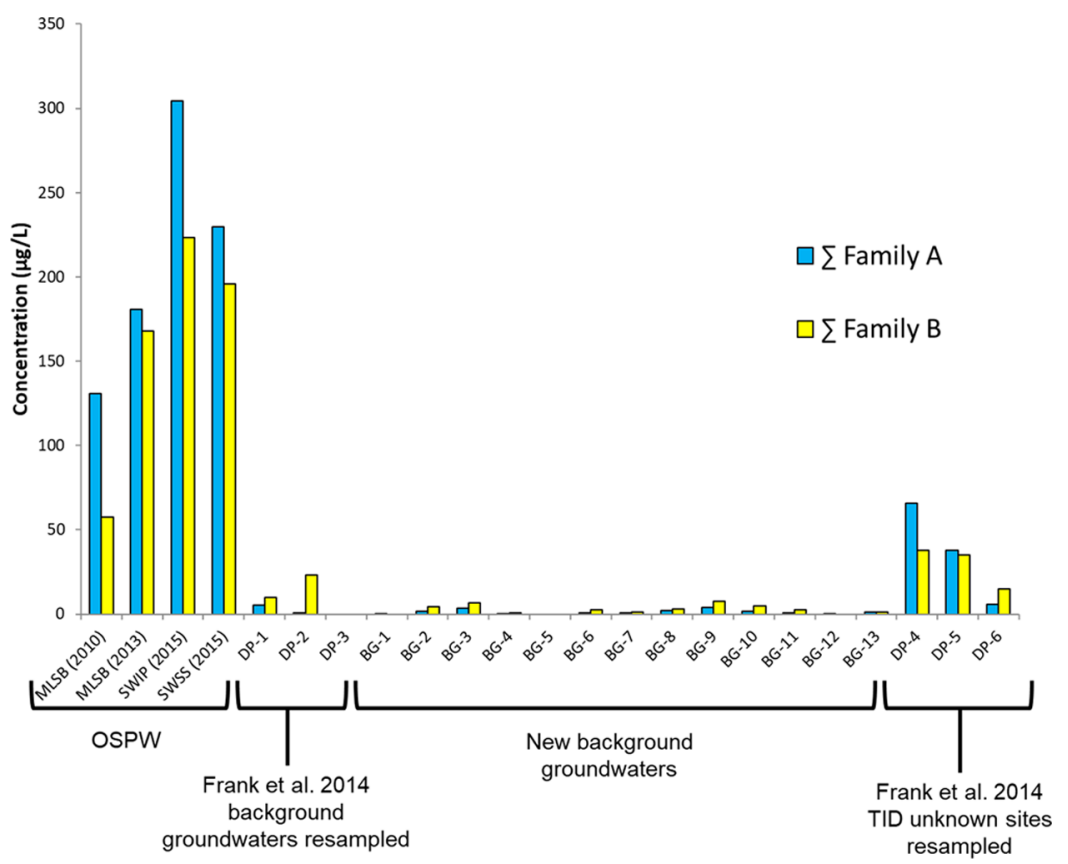

Figure 5. Total Family A and B concentrations in samples of OSPW, Background Groundwater, and Unknowns by Tar Island Dyke (TID, Table 1; Figure 1).

maintenance, and testing. Concentrations in groundwater affected by AFFF use may reach several orders of magnitude higher than those noted here for OSPW. ${ }^{45-47,62}$ For example, Anderson et al. ${ }^{62}$ reported mean groundwater concentrations corresponding to $309 \mu \mathrm{g} / \mathrm{L}$ PFOS, $20 \mu \mathrm{g} / \mathrm{L}$ PFHxS, and $7 \mu \mathrm{g} /$ L PFBS at U.S. air force operations. Similar to artificial sweeteners, PFAS should not be considered unique markers of OSPW. One pond with the lowest PFAS had just become operational when the pond was sampled. ${ }^{51}$

Generally, sweeteners and PFAS were found within the "inplume" samples (Figure 4B). Saccharin and the PFAS generally tracked the plume well in relation to the metrics previously used to track OSPW migration at this site (e.g., NAs, sodium, chloride $)^{13}$ and determined again here (Figure 4) with other Level-1 parameters (Figure 4; Figure S5). Plume concentrations of PFAS were elevated relative to the combined set of background groundwater in this study (Figure S9), which were comparable to groundwater samples from the United States: 1.26-11 ng/L PFBS, 1.88-45 ng/L PFHxS, and 3.25-3.41 ng/L PFOS. ${ }^{48}$ Acesulfame was only present in well samples $3 \mathrm{~A}$ and $4 \mathrm{~A}$, which are above the main OSPW-affected groundwater plume. Saccharin was also elevated in well 3A. These 2 wells are the shallowest within the well nests at locations 3 and 4 , suggesting an alternate source of wastewater or landfill contamination at or near ground surface in that area. The saccharin found at well 5B (clearly in front of the plume) may have a similar source.

This study is the first to report elevated concentrations of artificial sweeteners and PFAS in OSPW. However, concentrations were not elevated in all of the tailings ponds and both have other sources that may exist as part of mining operations. Thus, their use as OSPW-indicators should serve as part of a weight of evidence approach with other parameters and must be applied with proper consideration of site conditions.

Evaluation of Unknown Samples Adjacent to Tar Island Dyke. Frank et al. ${ }^{16}$ collected shallow groundwater from 3 locations adjacent to TID along the shoreline of the
Athabasca River (DP-4, DP-5, DP-6); 2 of these (DP-4, DP-5) were determined to be likely affected by OSPW. These same 3 locations were resampled in 2013 (Unknowns, Table 1) and then reassessed for OSPW-indicators, utilizing the advancements made in this study. Total Family A and B concentrations for these locations are presented in Figure 5, along with those of 4 OSPW samples collected from three ponds from two mining operations and the 16 background groundwater samples. All unknown samples had quantifiable concentrations, but only DP-4 and DP-5 had values (especially for Family A) notably above the maximum of the background groundwaters. Both had relatively low concentrations of components A5, A7, and A8 (Table S6), consistent with samples at the front of the Mildred Lake plume (Figure S6). These two samples also had elevated SFS signatures and concentrations of F and NA, while those of DP-6 were low (Figure S4). Note that it is possible that DP-6 has some minor OSPW-influence but, based on the data generated here, not enough to clearly distinguish it from background. Unfortunately, there are no data on artificial sweeteners and PFAS from the source at TID (Pond 1, now reclaimed), further complicating interpretation of these data. Regardless, the most noteworthy finding for the anthropogenic tracers was that the concentrations of PFHxS and PFOS at DP4 were greater than those of any OSPW sample (Figure S9). This may reflect an OSPW influence at DP-4, though it may also result from past PFAS uses around TID. The sweetener data for these 3 sites (Figure S8) was suggestive of an OSPW influence at DP4 and DP 6 but again may reflect other sources around TID.

A final assessment was conducted using a PCA with 31 chemistry parameters, including Family $\mathrm{A}$ and $\mathrm{B}$ (sums and individual components), $\mathrm{O}_{2} / \mathrm{O}_{4}, \mathrm{PFAS}$, artificial sweeteners, and a select group of inorganic compounds (typical screening parameters) and a Pearson Correlation matrix (Table S7). The biplot of this PCA (Figure 6) shows clear distinction along Component 1 ( $x$-axis; strongly aligned with Family A and B vectors) between OSPW-related samples (OSPW of MLSB 

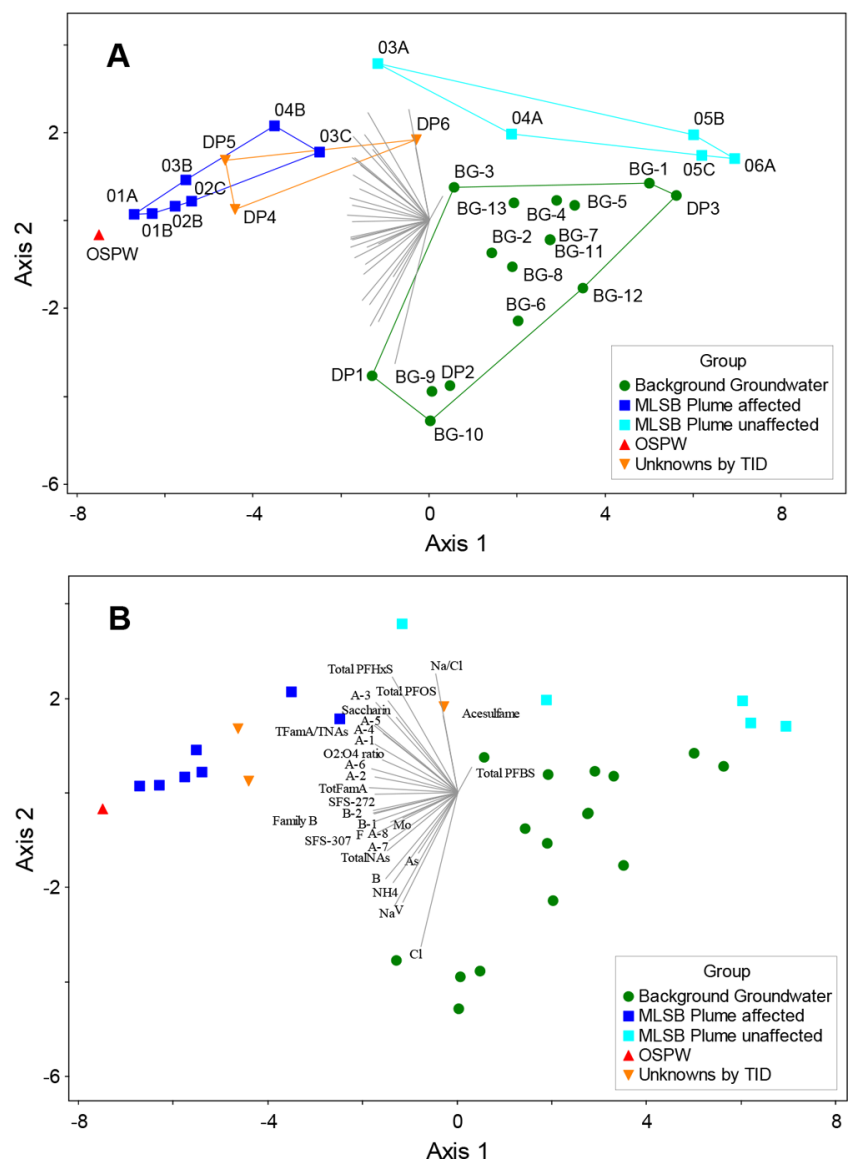

Figure 6. Biplot (first and second components) of the PCA of 31 chemical constituents in 32 water samples from the 4 sample groups (legend and Table 1; MLSB Plume split into OSPW-affected and nonaffected). Sample scores are indicated by symbols (according to group) and chemistry variable scores (loadings) are represented as vectors radiating from the origin. The chemical composition of a sample is indicated by its score relative to the variable vectors. The further from the origin a sample score's perpendicular projection on a vector is, the higher the concentration of the vector's chemical is likely to be in the sample. Samples that are chemically similar will plot near to each other. Plots A and B are identical but for (A) sample scores are labeled and enclosed by convex hulls according to sample group, and (B) chemistry variable loadings are labeled. For this PCA, $67.9 \%$ of the total variance was explained by the first 2 eigenvalues (components).

and in-plume; Table 1) and unaffected samples (background groundwaters and nonplume; Table 1). Samples DP-4 and DP5 fall in the region strictly related to MLSB OSPW and inplume wells, while DP-6 falls outside this area, close to wells $3 \mathrm{~A}$ and $4 \mathrm{~A}$ (nonplume; above and at the edge of the plume) and BG-3. Considering the above, this new evaluation of the resampled locations supports the earlier determination of Frank et al., ${ }^{16}$ providing more conclusive evidence of OSPWaffected groundwater reaching the Athabasca River system at locations DP-4 and DP-5.

Study Implications. In the present study, we sought to advance our previous methodology to distinguish OSPWaffected groundwater from background (particularly bitumeninfluenced) groundwater in Canada's oil sands region. The results identified the groups of Family A and B monoaromatic acids with clear concentration differences between an unprecedented sampling of OSPW and background ground- waters, including those influenced by natural bitumen. From our evaluations at a known OSPW plume, Family A isomers A1-A4 and A6 showed the greatest diagnostic potential. Thus, we conclude that the Family A acids represent the best single diagnostic metric to date. This is an advance from our previous work ${ }^{16}$ and is based on quantitative data, as these substances were quantified against an isomer isolated from OSPW by preparative $\mathrm{GC}$. We also determined that $\mathrm{O}_{2} / \mathrm{O}_{4}$ ratios are insufficient for distinguishing bitumen sources, thereby resolving the conflicting evidence for their diagnostic capabilities. $^{21,34,35}$

We are the first to report elevated concentrations of artificial sweeteners and PFAS in OSPW. All compound classes are highly mobile and persistent in groundwater; however, they were not found in all ponds, and given other common sources of these compounds in urban-industrial settings, we do not recommend them as definitive OSPW tracers. However, they would augment the weight of evidence assessment and therefore also advance our previous work. ${ }^{16}$ These advancements, coupled with the unprecedented sampling of industrial and natural sources, enabled the nontarget companion study by Milestone et al. ${ }^{52}$ to be conducted on the same extracts that could be assigned as OSPW-affected/nonaffected.

It is important to reiterate that this study focused solely on groundwater as the first recipient of possible OSPW seepage to facilitate and validate method development. Following future confirmations and availability of authentic standards of the Family A and B acids, analysis of these acids could be used to provide an assessment of OSPW-affected groundwater reaching nearby surface waters. However, given that it would not likely be feasible to analyze large numbers of samples for these analytes, sample screening is recommended. Screening parameters could include those used in the Level-1 analyses employed here and previously ${ }^{16}$ or other tracers reported in the literature, ${ }^{13,17,18,20,27-38}$ as incorporated into the PCA of Figure 6. It may be warranted in some cases to conduct supplemental analyses of anthropogenic classes (artificial sweeteners and/or PFAS) to provide further confidence of an OSPW-influence via a weight-of-evidence approach. It is important to reiterate that because the Family A acids are present naturally (Figures 1 and 5), these are unlikely to distinguish groundwater affected by low levels of OSPW. We note that the Milestone et al. ${ }^{52}$ identifies a small group of unknowns with strong diagnostic potential with postulated structures. Confirmations of these structures may ultimately advance the selectivity and sensitivity of the present methodology to enable future studies that could include measuring exact locations and fluxes of seepage.

Finally, this study supports the conclusions of Frank et al. ${ }^{16}$ that groundwater affected by OSPW is reaching the Athabasca River system beside TID at a few locations. The ecological implications of this, if any, are not immediately apparent. Ecosystem health assessments conducted at multiple stations over $100 \mathrm{~km}$ in the Athabasca River under the federal/ provincial Canada-Alberta Oil Sands Monitoring Plan showed that during 2012-2014, response patterns in benthic community assemblages were associated with nutrients and contaminants (metals and polyaromatic compounds; PACs) and that these in turn were associated with municipal sewage effluent and mining activities within the deposit. ${ }^{63}$ Fish population health assessments conducted in parallel showed similar responses indicative of nutrient enrichment (increased condition, internal fat stores) and exposure to PACs 
(induction of hepatic ethoxyresorufin-O-deethylase activity) relative to sites upstream of mining activity. ${ }^{64}$ At present, there is no linkage to any of these response patterns to OSPW seepage specifically; however, application of the methodology developed will now be able to confirm if seepage is entering surface waters.

This study has shown that the Family A and B monoaromatic acids with unknown chemical structures, and possibly acesulfame and perfluorinated surfactants, are components of the migratory OSPW mixtures beside TID. Other OSPW-derived organics, or in situ degradation products $^{56}$ with similar properties (e.g., water solubility), may also be present and pose undefined risks to aquatic biota. Determination of the drivers of toxicity within OSPW and impacted groundwaters, as well as the natural bitumen-affected groundwaters, is necessary to address the ecological relevance of OSPW-affected groundwater reaching surface waters. Given the complexities and inherent similarities in the chemical compositions of these sources, such studies need to be conducted carefully. Work in this area has been initiated, ${ }^{65,66}$ which will guide and inform the effects-based monitoring of fish populations and benthic communities of the Athabasca River watershed under the Canada-Alberta Oil Sands Monitoring Program.

\section{ASSOCIATED CONTENT}

\section{SI Supporting Information}

The Supporting Information is available free of charge at https://pubs.acs.org/doi/10.1021/acs.est.9b05040.

Photos of field work, sample collection details, PFAS Analysis, additional methods, information on sample preservation (PDF)

\section{AUTHOR INFORMATION}

\section{Corresponding Author}

L. Mark Hewitt - Environment and Climate Change Canada, Burlington, Canada; (1) orcid.org/0000-00023683-562X; Phone: (905)319-6924;

Email: mark.hewitt@canada.ca; Fax: (905)336-6430

\section{Other Authors}

James W. Roy - Environment and Climate Change Canada, Burlington, Canada; (1) orcid.org/0000-00021804-2917

Steve J. Rowland - University of Plymouth, Plymouth, U.K.

Greg Bickerton - Environment and Climate Change Canada, Burlington, Canada

Amila DeSilva - Environment and Climate Change Canada, Burlington, Canada; (1) orcid.org/0000-00025126-8854

John V. Headley - Environment and Climate Change Canada, Saskatoon, Canada

Craig B. Milestone - Davis Campus, Sheridan College, Brampton, Canada

Alan G. Scarlett - University of Plymouth, Plymouth, U.K.

Susan Brown - Environment and Climate Change Canada, Burlington, Canada
Christine Spencer - Environment and Climate Change Canada, Burlington, Canada

Charles E. West - University of Plymouth, Plymouth, U.K.

Kerry M. Peru - Environment and Climate Change Canada, Saskatoon, Canada

Lee Grapentine - Environment and Climate Change Canada, Burlington, Canada

Jason M.E. Ahad - Natural Resources Canada, Québec, Canada; 10 orcid.org/0000-0003-3246-3950

Hooshang Pakdel - INRS - Eau Terre Environnement, Québec, Canada

Richard A. Frank - Environment and Climate Change Canada, Burlington, Canada

Complete contact information is available at: https://pubs.acs.org/10.1021/acs.est.9b05040

\section{Notes}

The authors declare no competing financial interest.

\section{ACKNOWLEDGMENTS}

The authors wish to thank Matthew Dairon, William Govenlock, Ashley Hamilton, Ryan Levitt, Jason Miller, Kirsten Nickel, Jody Small, and Meagan Tobin (ECCCEdmonton); Jim Syrgiannis (ECCC-Regina); Andrew Basha and Bill Streeton (ECCC-Calgary); Thomas Clark, Katherine French, Braden Kralt, Amanda Malenica, John Spoelstra, André Talbot, Charles Talbot, Ruth Vanderveen, John Voralek and Catherine Wong (ECCC-Burlington); Rita Mroz (ECCCDartmouth); Brian Drover (ECCC-St. John's) and Margaret Klebek (retired) and Alex Oiffer (Alberta Environment and Parks) for providing field, technical, and logistical support. We thank Susan Brown, Pamela Collins, and Jerry Rajkumar (ECCC-Burlington) for inorganic analyses. Access to the Athabasca River was graciously provided by Northland Forest Products (Fort McMurray, Alberta). Appreciation is extended to the Fort McMurray offices of the former Alberta Environment and Sustainable Resource Development (now part of Alberta Agriculture and Forestry) and Water Survey of Canada for logistical support in Fort McMurray. Special thanks to Syncrude Canada Ltd., especially Frederick Payne and Femi Baiyewun, for providing support and site access to the Mildred Lake plume area. This work was partially funded under the Oil Sands Monitoring Program and is a contribution to the Program but does not necessarily reflect the position of the Program. A portion of the funding for the GCxGC-TOF-MS instrumentation was kindly provided by the European Research Council (project OUTREACH, Grant number: 228149 to SJR).

\section{REFERENCES}

(1) Alberta Energy Regulator Alberta's energy reserves 2014 and supply/demand outlook 2015-2024; ST98-2015; 2015.

(2) Canadian Association of Petroleum Producers Crude oil: Forecast, markets and transportation; 2016; $\mathrm{p} 43$.

(3) Nero, V.; Farwell, A.; Lee, L. E. J.; Van Meer, T.; MacKinnon, M. D.; Dixon, D. G. The effects of salinity on naphthenic acid toxicity to yellow perch: Gill and liver histopathology. Ecotoxicol. Environ. Saf. 2006, 65, 252-264.

(4) Peters, L. E.; MacKinnon, M. D.; Van Meer, T.; van den Heuvel, M. R.; Dixon, D. G. Effects of oil sands process-affected waters and naphthenic acids on yellow perch (Perca flavescens) and Japanese 
medaka (Orizias latipes) embryonic development. Chemosphere 2007, 67, 2177-2183.

(5) Lister, A.; Nero, V.; Farwell, A.; Dixon, D. G.; Van Der Kraak, G. Reproductive and stress hormone levels in goldfish (Carassius auratus) exposed to oil sands process-affected water. Aquat. Toxicol. 2008, 87, 170-177.

(6) Kavanagh, R. J.; Frank, R. A.; Oakes, K. D.; Servos, M. R.; Young, R. F.; Fedorak, P. M.; MacKinnon, M. D.; Solomon, K. R.; Dixon, D. G.; Van Der Kraak, G. Fathead minnow (Pimephales promelas) reproduction is impaired in aged oil sands process-affected waters. Aquat. Toxicol. 2011, 101, 214-220.

(7) Li, C.; Li, F.; Stafford, J.; Belosevic, M.; Gamal El-Din, M. The toxicity of oil sands process-affected water (OSPW): A critical review. Sci. Total Environ. 2017, 601-602, 1785-1802.

(8) Leung, S. S.; MacKinnon, M. D.; Smith, R. E. H. The ecological effects of naphthenic acids and salts on phytoplankton from the Athabasca oil sands region. Aquat. Toxicol. 2003, 62, 11-26.

(9) Bartlett, A. J.; Frank, R.; Gillis, P. L.; Parrott, J.; Marentette, J. R.; Brown, L. R.; Hooey, T.; Vanderveen, R.; McInnis, R.; Brunswick, P.; Shang, D.; Headley, J. V.; Peru, K. M.; Hewitt, L. M. Toxicity of naphthenic acids to invertebrates: Extracts from oil sands processaffected water versus commercial mixtures. Environ. Pollut. 2017, 227, 271-279.

(10) Royal Society of Canada Expert Panel Environmental and Health Impacts of Canada's Oil Sands Industry; 2010.

(11) USEPA Design and Evaluation of Tailings Dams; NTIS PB94201845; Office of Solid Waste, Special Waste Branch: Washington, DC USA, 1994; p 64.

(12) Ferguson, G. P.; Rudolph, D. L.; Barker, J. F. Hydrodynamics of a large oil sand tailings impoundment and related environmental implications. Can. Geotech. J. 2009, 46, 1446-1460.

(13) Oiffer, A. A. L.; Barker, J. F.; Gervais, F. M.; Mayer, K. U.; Ptacek, C. J.; Rudolph, D. L. A detailed field-based evaluation of naphthenic acid mobility in groundwater. J. Contam. Hydrol. 2009, 108, 89-106.

(14) Yasuda, N.; Thomson, N. R.; Barker, J. F. Performance evaluation of a tailings pond seepage collection system. Can. Geotech. J. 2010, 47, 1305-1315.

(15) Parrott, J. L.; McMaster, M. E.; Hewitt, L. M. A decade of research on the environmental impacts of pulp and paper mill effluents in Canada: Development and application of fish bioassays. J. Toxicol. Environ. Health, Part B 2006, 9 (4), 297-317.

(16) Frank, R. A.; Roy, J. W.; Bickerton, G.; Rowland, S. J.; Headley, J. V.; Scarlett, A. G.; West, C. E.; Peru, K. M.; Conly, F. M.; Hewitt, L. M. Profiling oil sands mixtures from industrial developments and natural groundwaters for source identification. Environ. Sci. Technol. 2014, 48 (5), 2660-2670.

(17) Hunter, G. P. Investigation of groundwater flow within an oil sands tailings impoundment and environmental implications. University of Waterloo: 2001.

(18) MacKinnon, M. D.; Kampala, G.; Marsh, B.; Fedorak, P. M.; Guigard, S., Indicators for assessing transport of oil sands processaffected waters. In Bringing groundwater quality research to the watershed (Proceedings of GQ2004 International Conference of Groundwater Quality), Thomson, N. R., Ed. IAHS Press: 2005; Vol. 297, pp $71-80$.

(19) Ross, M. S.; Pereira, A. d. S.; Fennell, J.; Davies, M.; Johnson, J.; Sliva, L.; Martin, J. W. Quantitative and qualitative analysis of naphthenic acids in natural waters surrounding the Canadian oil sands industry. Environ. Sci. Technol. 2012, 46, 12796-12805.

(20) Roy, J. W.; Bickerton, G.; Frank, R. A.; Grapentine, L.; Hewitt, L. M. Assessing risks of shallow riparian groundwater quality near an oil sands tailings pond. Groundwater 2016, 54 (4), 545-558.

(21) Sun, C.; Shotyk, W.; Cuss, C. W.; Donner, M. W.; Fennell, J.; Javed, M.; Noernberg, T.; Poesch, M.; Pelletier, R.; Sinnatamby, N.; Siddique, T.; Martin, J. W. Characterization of naphthenic acids and other dissolved organics in natural water from the Athabasca oil sands region, Canada. Environ. Sci. Technol. 2017, 51 (17), 9524-9532.
(22) Rowland, S. J.; Scarlett, A. G.; Jones, D.; West, C. E.; Frank, R. A. Diamonds in the rough: Identification of individual naphthenic acids in oil sands process water. Environ. Sci. Technol. 2011, 45, 31543159.

(23) Bowman, D. T.; Slater, G. F.; Warren, L. A.; McCarry, B. E. Identification of individual thiophene-, Indane-, tetralin-, cyclohexane-, and adamantane-type carboxylic acids in composite tailings pore water from Alberta oil sands. Rapid Commun. Mass Spectrom. 2014, 28, 2075-2083.

(24) Wilde, M. J.; West, C. E.; Scarlett, A. G.; Jones, D.; Frank, R. A.; Hewitt, L. M.; Rowland, S. J. Bicyclic naphthenic acids in oil sands process water: Identification by comprehensive multidimensional gas chromatography-mass spectrometry. Journal of Chromatography A 2015, 1378, 74-87.

(25) Wilde, M. J.; Rowland, S. J., Structural Identification of Petroleum Acids by Conversion to Hydrocarbons and Multidimensional Gas Chromatography-Mass Spectrometry. Anal. Chem. 2015, (in press). 878457

(26) Wilde, M. J.; Rowland, S. J. Naphthenic acids in oil sands process waters: Identification by conversion of the acids or esters to hydrocarbons. Org. Geochem. 2018, 115, 188-196.

(27) Ahad, J. M. E.; Pakdel, H.; Savard, M. M.; Simard, M.-C.; Smirnoff, A. Extraction, separation, and intramolecular carbon isotope characterization of Athabasca oil sands acids in environmental samples. Anal. Chem. 2012, 84, 10419-10425.

(28) Baker, K. M. Identification of process water in a surficial aquifer at Syncrude's Mildred Lake Site. University of Waterloo: 1999.

(29) Barrow, M. P.; Peru, K. M.; Fahlman, B.; Hewitt, L. M.; Frank, R. A.; Headley, J. V. Beyond naphthenic acids: environmental screening of water from the Athabasca region using APPI-FTICR mass spectrometry. J. Am. Soc. Mass Spectrom. 2015, 26 (9), 15081521.

(30) Bauer, A. E.; Frank, R. A.; Headley, J. V.; Peru, K. M.; Farwell, A. J.; Dixon, D. G. Toxicity of oil sands acid-extractable organic fractions to freshwater fish: Pimephales promelas (fathead minnow) and Oryzias latipes (Japanese medaka). Chemosphere 2017, 171, 168176.

(31) Gibson, J. J.; Birks, S. J.; Moncur, M.; Yi, Y.; Tattrie, K.; Jasechko, S.; Richardson, K.; Eby, P. Isotopic and geochemical tracers for fingerprinting process-affected waters in the oil sands industry: A pilot study; Oil Sands Research and Information Network; University of Alberta, School of Energy and the Environment: Edmonton, AB. OSRIN Report No. TR-12: 2011; p 109.

(32) Savard, M. M.; Ahad, J. M. E.; Gammon, P.; Calderhead, A. I.; Rivera, A.; Martel, R.; Klebek, M.; Headley, J. V.; Lefebvre, R.; Welsh, B.; Smirnoff, A.; Pakdel, H.; Benoit, N.; Liao, S.; Jautzy, J.; Gagnon, C.; Vaive, J.; Girard, I.; Peru, K. M. A local test study distinguishes natural from anthropogenic groundwater contaminants near an Athabasca oil sands mining operation; Geological Survey of Canada, Open File 7195 2012, 140.

(33) Yi, Y.; Gibson, J.; Birks, J.; Han, J.; Borchers, C. H. Comment on "Profiling Oil Sands Mixtures from Industrial Developments and Natural Groundwaters for Source Identification. Environ. Sci. Technol. 2014, 48 (18), 11013-11014.

(34) Yi, Y.; Han, J.; Jean Birks, S.; Borchers, C. H.; Gibson, J. J. Profiling of dissolved organic compounds in the oil sands region using complimentary liquid-liquid extraction and ultrahigh resolution Fourier transform mass spectrometry. Environ. Earth Sci. 2017, 76 (24), 828.

(35) Huang, R.; Chen, Y.; Meshref, M. N. A.; Chelme-Ayala, P.; Dong, S.; Ibrahim, M. D.; Wang, C.; Klamerth, N.; Hughes, S. A.; Headley, J. V.; Peru, K. M.; Brown, C.; Mahaffey, A.; Gamal El-Din, M. Monitoring of classical, oxidized, and heteroatomic naphthenic acids species in oil sands process water and groundwater from the active oil sands operation area. Sci. Total Environ. 2018, 645, 277285.

(36) Harkness, J. S.; Warner, N. R.; Ulrich, A.; Millot, R.; Kloppmann, W.; Ahad, J. M. E.; Savard, M. M.; Gammon, P.; Vengosh, A. Characterization of the boron, lithium, and strontium 
isotopic variations of oil sands process-affected water in Alberta, Canada. Appl. Geochem. 2018, 90, 50-62.

(37) Shotyk, W.; Bicalho, B.; Cuss, C. W.; Donner, M. W.; GrantWeaver, I.; Haas-Neill, S.; Javed, M. B.; Krachler, M.; Noernberg, T.; Pelletier, R; Zaccone, C. Trace metals in the dissolved fraction $(<0.45 \mu \mathrm{m})$ of the lower Athabasca River: Analytical challenges and environmental implications. Sci. Total Environ. 2017, 580, 660-669.

(38) Donner, M. W.; Javed, M. B.; Shotyk, W.; Francesconi, K. A.; Siddique, T. Arsenic speciation in the lower Athabasca River watershed: A geochemical investigation of the dissolved and particulate phases. Environ. Pollut. 2017, 224, 265-274.

(39) Rowland, S. J.; West, C. E.; Jones, D.; Scarlett, A. G.; Frank, R. A.; Hewitt, L. M. Steroidal aromatic 'naphthenic acids' in oil sands process-affected water: Structural comparisons with environmental estrogens. Environ. Sci. Technol. 2011, 45, 9806-9815.

(40) West, C. E.; Scarlett, A. G.; Pureveen, J.; Tegelaar, E.; Rowland, S. J. Abundant naphthenic acids in oil sands process-affected water: Studies by synthesis, derivatisation and two-dimensional gas chromatography/high-resolution mass spectrometry. Rapid Commun. Mass Spectrom. 2013, 27, 357-365.

(41) Bowman, D. T.; Warren, L. A.; McCarry, B. E.; Slater, G. F. Profiling of individual naphthenic acids at a composite tailings reclamation fen by comprehensive two-dimensional gas chromatography-mass spectrometry. Sci. Total Environ. 2019, 649, 1522-1531.

(42) Headley, J. V.; Barrow, M. P.; Peru, K. M.; Fahlman, B.; Frank, R. A.; Bickerton, G.; McMaster, M. E.; Parrott, J.; Hewitt, L. M. Preliminary fingerprinting of Athabasca oil sands polar organics in environmental samples using electrospray ionization Fourier transform ion cyclotron resonance mass spectrometry. Rapid Commun. Mass Spectrom. 2011, 25, 1899-1909.

(43) Pereira, A. S.; Martin, J. W. Exploring the complexity of oil sands process-affected water by high efficiency supercritical fluid chromatography/orbitrap mass spectrometry. Rapid Commun. Mass Spectrom. 2015, 29 (8), 735-744.

(44) Van Stempvoort, D. R.; Roy, J. W.; Brown, S. J.; Bickerton, G. Artificial sweeteners as potential tracers in groundwater in urban environments. J. Hydrol. 2011, 401 (1), 126-133.

(45) Moody, C. A.; Hebert, G. N.; Strauss, S. H.; Field, J. A. Occurrence and persistence of perfluorooctanesulfonate and other perfluorinated surfactants in groundwater at a fire-training area at Wurtsmith Air Force Base, Michigan, USA. J. Environ. Monit. 2003, 5 (2), 341-345.

(46) Bräunig, J.; Baduel, C.; Heffernan, A.; Rotander, A.; Donaldson, E.; Mueller, J. F. Fate and redistribution of perfluoroalkyl acids through AFFF-impacted groundwater. Sci. Total Environ. 2017, 596$597,360-368$.

(47) Gobelius, L.; Hedlund, J.; Dürig, W.; Tröger, R.; Lilja, K.; Wiberg, K.; Ahrens, L. Per- and Polyfluoroalkyl Substances in Swedish Groundwater and Surface Water: Implications for Environmental Quality Standards and Drinking Water Guidelines. Environ. Sci. Technol. 2018, 52 (7), 4340-4349.

(48) Boone, J. S.; Vigo, C.; Boone, T.; Byrne, C.; Ferrario, J.; Benson, R.; Donohue, J.; Simmons, J. E.; Kolpin, D. W.; Furlong, E. T.; Glassmeyer, S. T. Per- and polyfluoroalkyl substances in source and treated drinking waters of the United States. Sci. Total Environ. 2019, 653, 359-369.

(49) Roy, J. W.; Bickerton, G. A proactive screening approach for detecting groundwater contaminants along urban streams at the reach-scale. Environ. Sci. Technol. 2010, 44, 6088-6094.

(50) 2320 ALKALINITY (2017). In Standard Methods For the Examination of Water and Wastewater.

(51) Frank, R. A.; Milestone, C. B.; Rowland, S. J.; Headley, J. V.; Kavanagh, R. J.; Lengger, S. K.; Scarlett, A. G.; West, C. E.; Peru, K. M.; Hewitt, L. M. Assessing spatial and temporal variability of acidextractable organics in oil sands process-affected waters. Chemosphere 2016, 160, 303-313.

(52) Milestone, C. B., Sun, C.; Martin, J.; Bickerton, G.; Roy, J.; Frank, R.A.; Hewitt, L.M., Nontarget profiling of bitumen influenced waters for the identification of tracers unique to oil sands processed- affected water (OSPW) in the Athabasca watershed of Alberta, Canada. Sci. Total Environ. Submitted January 2020.

(53) Reichenbach, S. E.; Kottapalli, V.; Ni, M.; Visvanathan, A. Computer language for identifying chemicals with comprehensive two-dimensional gas chromatography and mass spectrometry. Journal of Chromatography A 2005, 1071 (1), 263-269.

(54) De Silva, A. O.; Spencer, C.; Scott, B. F.; Backus, S.; Muir, D. C. G. Detection of a Cyclic Perfluorinated Acid, Perfluoroethylcyclohexane Sulfonate, in the Great Lakes of North America. Environ. Sci. Technol. 2011, 45 (19), 8060-8066.

(55) McCune, B. M. J. M. PC-ORD. Multivariate Analysis of Ecological Data 7.02; MjM Software: Gleneden Beach, Oregon, U.S.A., 2016.

(56) Ahad, J. M. E.; Pakdel, H.; Gammon, P. R.; Siddique, T.; Kuznetsova, A.; Savard, M. M. Evaluating in situ biodegradation of 13C-labelled naphthenic acids in groundwater near oil sands tailings ponds. Sci. Total Environ. 2018, 643, 392-399.

(57) Robertson, W. D.; Van Stempvoort, D. R.; Roy, J. W.; Brown, S. J.; Spoelstra, J.; Schiff, S. L.; Rudolph, D. R.; Danielescu, S.; Graham, G. Use of an Artificial Sweetener to Identify Sources of Groundwater Nitrate Contamination. Groundwater 2016, 54 (4), 579-587.

(58) Canada, E. Ecological Screening Assessment Report on Perfluorooctane Sulfonate, Its Salts and Its Precursors that Contain the C8F17SO2 or C8F17SO3, or C8F17SO2N Moiety.; Environment Canada: June, 2006., 2006; p 81.

(59) Weiner, B.; Yeung, L. W. Y.; Marchington, E. B.; D’Agostino, L. A.; Mabury, S. A. Organic fluorine content in aqueous film forming foams (AFFFs) and biodegradation of the foam component 6:2 fluorotelomermercaptoalkylamido sulfonate (6:2 FTSAS). Environmental Chemistry 2013, 10 (6), 486-493.

(60) Dauchy, X.; Boiteux, V.; Colin, A.; Bach, C.; Rosin, C.; Munoz, J.-F. Poly- and Perfluoroalkyl Substances in Runoff Water and Wastewater Sampled at a Firefighter Training Area. Arch. Environ. Contam. Toxicol. 2019, 76 (2), 206-215.

(61) Milley, S. A.; Koch, I.; Fortin, P.; Archer, J.; Reynolds, D.; Weber, K. P. Estimating the number of airports potentially contaminated with perfluoroalkyl and polyfluoroalkyl substances from aqueous film forming foam: A Canadian example. J. Environ. Manage. 2018, 222, 122-131.

(62) Anderson, R. H.; Long, G. C.; Porter, R. C.; Anderson, J. K. Occurrence of select perfluoroalkyl substances at U.S. Air Force aqueous film-forming foam release sites other than fire-training areas: Field-validation of critical fate and transport properties. Chemosphere 2016, 150, 678-685.

(63) Culp, J. C., Glozier, N. E., Baird, D. J., Wrona, F. J., Brua, R. B., Ritcey, A. L., Peters, D. L., Casey, R., Choung, C. B., Curry, C. J., Halliwell, D., Keet, E., Kilgour, B., Kirtk, J., Lento, J., Luiker, E., Suzanne, C.. Assessing ecosystem health in benthic macroinvertebrate assemblages of the Athabasca River mainstem, tributaries and PeaceAthabasca Delta.; Environment and Climate Change Canada: June 2018, 2018; p 82.

(64) McMaster, M., Parrott, J., Bartlett, A., Gagne, F., Evans, M., Tetreault, G., Keith, H., Gee, J. Aquatic ecosystem health assessment of the Athabasca River mainstem and tributaries using fish health and fish and invertebrate toxicological testing.; Environment and Climate Change Canada: June 2018, 2018; p 76.

(65) Bauer, A. E.; Frank, R. A.; Headley, J. V.; Milestone, C. M.; Batchelor, S.; Peru, K. M.; Rudy, M. D.; Barrett, S. E.; Vanderveen, R.; Dixon, D. G.; Hewitt, L. M. A preparative method for the isolation and fractionation of dissolved organics from bitumen-influenced waters. Sci. Total Environ. 2019, 671, 587-597.

(66) Bauer, A. E. L. M. H.; Parrott, J. L.; Bartlett, A. J.; Gillis, P. L.; Rudy, M. D.; Vanderveen, R.; Barrett, S. E.; Campbell, S. D.; Brown, L.; Deeth, L. E.; Farwell, A. J.; Dixon, D. G.; Frank, R. A. The toxicity of organic fractions from aged oil sands process-affected water to aquatic species. Sci. Total Environ. 2019, 669, 702-710. 